\title{
Non-Contact, Real-Time Laser-Induced Fluorescence Detection and Monitoring of Microbial Contaminants on Solid Surfaces Before, During and After Decontamination
}

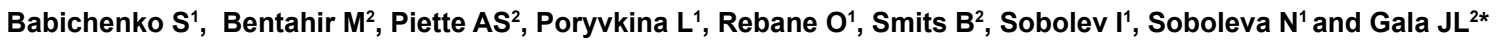 \\ ${ }^{1}$ LDI Innovation OU, Osmussaare 8, Tallinn, Estonia \\ ${ }^{2}$ Center for Applied Molecular Technologies, Institute of Clinical and Experimental Research, Université catholique de Louvain, Tour Claude Bernard, Brussels, Belgium
}

\begin{abstract}
A real-time detection and monitoring (RTDM) of microbial contamination on solid surfaces is mandatory in a range of security, safety and bio-medical applications where surfaces are exposed to accidental, natural or intentional microbial contamination. This work presents a new device, the BC-Sense, which allows a rapid and user-friendly RTDM of microbial contamination on various surfaces while assessing the decontamination kinetics and degree of cleanliness. The BC-Sense LIDAR (Light Detection and Ranging) device uses the Laser-Induced Fluorescence (LIF) method based on dual wavelength sensing with multispectral pattern recognition system to rapidly detect microbial contamination on a solid surface. Microbial simulants (bacteria, bacterial spores, fungal conidia and virus) were spread at varying concentrations on a panel of solid surfaces which were assessed by BC-Sense. The spectra of dead and living $E$. coli showed differences at various sensing wavelengths. The limit of detection (LoD) of $E$. coli and MS2 virus was $2.9 \times 10^{4}$ and $9.5 \times 10^{4} \mathrm{CFU}$ and PFU/ $/ \mathrm{cm}^{2}$, respectively. Random samples $(n=200)$ tested against a training dataset $(n=800)$ were optimally discriminated for contamination versus background with a threshold of predicted response $(P R)>0.55$ and $<0.4$, respectively. Decontamination kinetics on copper surface showed a complete disappearance of fluorescence in 1 min with MS2 versus $>10$ min with spores and $E$. coli.
\end{abstract}

Keywords: Microbial contamination; Real-time detection and monitoring (RTDM); Laser-Induced Fluorescence (LIF)

\section{Introduction}

The common thread of microbial contamination is the exposition of solid surfaces to the accidental, natural or intentional deposit of micrometers and submicrometer-sized particles consisting of contaminating biological agents, loosely defined as microbial contaminants. In many cases, the need for assessing readily and rapidly the materiality and extent of a biological contamination is of paramount importance [1]. This commonly applies to incidents where an accidental, natural or deliberate release of microbial contaminants is suspected. Scenarios where real-time detection and monitoring (RTDM) is mandatory can synthetically be split in a preventive versus reactive approach. The preventive approach applies to many situations, e.g., to microbiological analyses of surfaces in food-processing industry where RTDM is part of the tools used to control the hygiene of food products, to the microbial control of industrial and hospital cleanroom facilities, to the control of cleanliness in operating theatres, and as a biosafety measure in microbiological or medical laboratories. The reactive approach occurs after the suspicion of a deliberate or accidental release of biological agents. It is used to assess the extent of surface contamination, delineate as precisely as possible the area to be excluded for non-authorized persons, and guide the sampling procedures while avoiding unnecessary random sampling. Assessment of the decontamination efficiency, which is commonly quoted as "how clean is clean enough", takes place after the cleaning phase following the dispersion of biological aerosol [2]. Whether in a civilian, public health or military context, it undoubtedly remains a key issue.

Conventional methods require the samples to be taken in the 'right spot' to accurately assess the presence and/or distribution of the microbial flora. It is however impossible to sample large areas/ volumes or continuously sample with current technology. Due to biosafety issues, sample contact itself is a major concern in most situations. Technologies capable of providing a non-contact, real-time detection of microbiological contaminants and real-time assessment during and after decontamination are extremely scarce. They include fluorescence (photoluminescence) spectroscopy, Raman spectroscopy, Laser-Induced Breakdown Spectroscopy (LIBS) and hyperspectral imaging [3-7]. Each of these techniques has its merits and drawbacks. Compared with fluorescence, the Raman spectroscopy would need power more than one order of magnitude and a more stable wavelength to generate a signal-to-noise ratio that is exploitable irrespective of the absence of the fluorescence background known to be a hindrance. LIBS spectroscopy would need a lot more power per pulse and a higherresolution and lower throughput spectrometer while the hyperspectral imaging system might not be specific enough and needs ambient light. The genuine fluorescence high sensitivity and selectivity are therefore considered to be suitable and effective features to use in the RTDM of small amounts of microbial contaminants on surfaces at medium range distances. The intrinsic fluorescence of various biomolecules depends not only on the concentration of fluorescing molecules (e.g., tryptophan) contained in the proteins of biological agents, but also depends on the molecular composition of the immediate surroundings (i.e., the chemical background/solvent). This can cause large changes

*Corresponding author: Gala JL, Center for Applied Molecular Technologies, Institute of Clinical and Experimental Research, Université catholique de Louvain Tour Claude Bernard, Avenue Hippocrate 54-55, B1.54.01, 1200 Brussels, Belgium, Tel: +3227643165; E-mail: jean-luc.gala@uclouvain.be

Received May 31, 2018; Accepted June 11, 2018; Published June 18, 2018

Citation: Babichenko S, Bentahir M, Piette AS, Poryvkina L, Rebane O, et al (2018) Non-Contact, Real-Time Laser-Induced Fluorescence Detection and Monitoring of Microbial Contaminants on Solid Surfaces Before, During and After Decontamination. J Biosens Bioelectron 9: 255. doi: 10.4172/2155-6210.1000255

Copyright: (c) 2018 Babichenko S, et al. This is an open-access article distributed under the terms of the Creative Commons Attribution License, which permits unrestricted use, distribution, and reproduction in any medium, provided the original author and source are credited. 
Citation: Babichenko S, Bentahir M, Piette AS, Poryvkina L, Rebane O, et al. (2018) Non-Contact, Real-Time Laser-Induced Fluorescence Detection and Monitoring of Microbial Contaminants on Solid Surfaces Before, During and After Decontamination. J Biosens Bioelectron 9: 255. doi: $10.4172 / 2155-6210.1000255$

Page 2 of 9

in registered spectra due to the energy transfer or quenching of the emitted fluorescence spectrum. Consequently, the shape of the induced fluorescence spectrum reflects specifically the molecular composition of the assessed area, hence can serve for detection and monitoring of various microbiological agents $[8,9]$.

This paper describes the development of a stand-off BC-Sense LIDAR system using a Laser-Induced Fluorescence (LIF) method based on dual wavelength sensing with multispectral pattern recognition. The purpose of this tool is to carry out non-contact (short range standoff) RTDM of solid surfaces. A panel of biological agents were spread on various surfaces as a model of natural, accidental or intentional biological contaminations. The BC-Sense device was used to assess the efficiency of decontamination through RTDM of residual microbial contaminants. This paper presents the first evidence of the validity of this methodological approach and the feasibility of using it for this type of application.

\section{Materials and Methods}

\section{Description of the BC-sense device}

The BC-sense LIDAR system consists of 2 excimer lasers which induce the fluorescence, a telescope to collect the backscattered fluorescence signal, a spectrometer with switchable long-pass filters, an intensified camera for detecting low-level signals, and other components including the electronic controller (Figure 1a).

Fluorescence from the sample is excited by a $248 \mathrm{~nm}$ krypton fluoride $(\mathrm{KrF})$ laser with $\sim 5 \mathrm{~mJ}$ energy and a $351 \mathrm{~nm}$ xenon fluoride (XeF) laser with $\sim 2 \mathrm{~mJ}$ pulse energy. Maximum pulse repetition rate of the lasers is $10 \mathrm{~Hz}$ (reduced from $100 \mathrm{~Hz}$ of the lasers). The working range of the device is from 5 to $\sim 20 \mathrm{~m}$ and it is meant to be operated in indoor (dry) conditions. The optical scheme of the LIDAR is co-axial, which means that the laser beam and the telescope are always aligned along the optical axis of the device. This means that changing the distance between the sensor and the surface to assess does not require to adjust the basic optical setup of the LIDAR nor to have moving parts when the focus distance ranges from 5 to $20 \mathrm{~m}$. Moreover, the reflective-only optical scheme means that chromatic aberrations or spectral shifts with distance are unlikely. The co-axial and achromatic alignment allows for continuous spectral measurement without requiring constant adjustments by the operator or the software.

The laser light is directed onto the sample in trains/sequences of consecutive pulses (10 pulses at both wavelengths by default). The backscattered light, containing scattering and fluorescence flux, is collected by an off-axis parabolic mirror telescope, and the reflected (same-wavelength) laser light is removed before entering the spectrometer by switchable longpass filters. The fluorescence at each excitation wavelength is dispersed into a spectrum with concave diffraction grating. The spectrum is recorded by intensified time-gated multi-channel linear detector. It allows the system to be operated by users in day light conditions. The spectral resolution is about $10 \mathrm{~nm}$ in the wavelength range of 300 to $600 \mathrm{~nm}$. The microcontroller manages the operational cycle of the system and sends the data package for storage and analysis.

The BC-Sense device can be carried by two persons and operated on a special trolley (Figure 1b). The dimensions of the LIDAR device are $680 \times 410 \times 337 \mathrm{~mm}$ and it weighs $40 \mathrm{~kg}$. A special trolley was created to allow for easily directing and aiming the laser beam from the LIDAR onto the target. A green laser pointer was installed into the LIDAR to help aim target areas. The power consumption of the aircooled and wall-plug-powered device is $200 \mathrm{~W}$.

\section{Principles of use of the BC-Sense device}

Two excitation wavelengths ( 248 and $351 \mathrm{~nm}$ ) were used to measure fluorescence spectra of the samples. Excitation at $248 \mathrm{~nm}$ induces the fluorescence of proteins contained in all microorganisms, namely tryptophan, tyrosine and phenylalanine amino acids, and resulted in an emission of fluorescence around $350 \mathrm{~nm}$ [9].

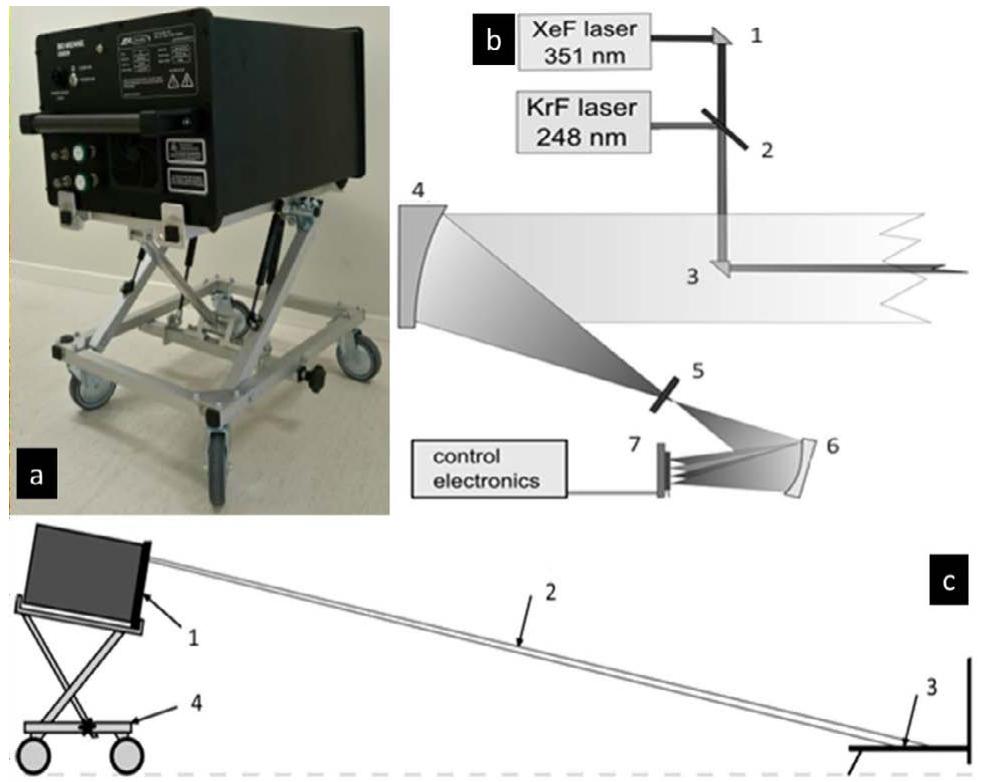

Figure 1: BC-Sense LIDAR device. (a) External view with carrying trolley; (b) Layout: 1,3- FS prisms, 2- dichroic filter, 4- telescope mirror, 5- switchable filter, 6- diffraction grating, 7- gated linear detector; (c) Experimental setup: 1 - BC-Sense device, 2 - laser beam at $\sim 10$ degree angle below horizontal level, 3 - sample on horizontal copper surface, 4 - trolley. 
Citation: Babichenko S, Bentahir M, Piette AS, Poryvkina L, Rebane O, et al. (2018) Non-Contact, Real-Time Laser-Induced Fluorescence Detection and Monitoring of Microbial Contaminants on Solid Surfaces Before, During and After Decontamination. J Biosens Bioelectron 9: 255. doi: $10.4172 / 2155-6210.1000255$

Page 3 of 9

Excitation at $351 \mathrm{~nm}$ induces the fluorescence of reduced form of nicotinamide adenine dinucleotide (NADH), which is a coenzyme having major metabolic functions in bacterial and fungal cells but not in viruses, and of its phosphate form (NADPH), with an emission around $450 \mathrm{~nm}[10]$.

A direct optical path (i.e., without mirrors) was used to detect the panel of biological contaminants in their respective media. For each assay, the sample was placed on the top of on a horizontal copper surface, a material devoid of any background fluorescence. Positioned at a distance of about $6 \mathrm{~m}$, the laser beam was then pointed at the area of the copper surface contaminated with the biological sample and the laser-induced fluorescence spectra were measured and recorded for later analysis (Figure 1c). For each sample, an average spectrum was recorded over 10 laser shots to increase the signal to noise ratio.

\section{Selection and production of biological agents}

For this study, bacterial, bacterial spores, fungal conidia and viral models were used as surface contaminants. E. coli, Gram negative bacteria, is a widely used bacterial model in laboratory studies [11]. In the current study, the E. coli DSM 11250 strain (Deutsche Sammlung von Mikroorganismen und Zellkulturen, Germany) was used. B. thuringiensis, a gram positive spore forming bacteria, is the second most studied bacteria and is often used as a model, especially in decontamination studies as a surrogate for its close-neighbour Bacillus anthracis, which is a bio-warfare agent $[12,13]$. The B. thuringiensis subsp. aizawai strain ABTS-1857 was grown from Xentari WG, a commercial B. thuringiensis-based insecticide (Bayer Crop Science SA$\mathrm{NV}$, Belgium). Both E. coli and B. thuringiensis strains were plated on LB agar (LB broth - VWR chemicals, Belgium; BactoTM Agar - Becton, Dickinson and company, France) petri dish and grown overnight at $37^{\circ} \mathrm{C}$. A single colony was then transferred to a LB broth and grown overnight $\left(37^{\circ} \mathrm{C}, 140 \mathrm{rpm}\right)$. The $\mathrm{CFU} / \mathrm{mL}$ was determined as $3.7 \times$ $10^{9} \mathrm{CFU} / \mathrm{mL}$ for E. coli and $7.9 \times 10^{7} \mathrm{CFU} / \mathrm{mL}$ for B. thuringiensis. To prevent a high background noise due to the culture media (LB) content in tryptone and yeast extract, all biological samples used for BC-Sense measurements were re-suspended and diluted in an isotonic phosphate-buffered saline (PBS). E. coli and B. thuringiensis agents were washed, resuspended in PBS buffer and heat inactivated (Julabo Sw22 water bath $-99^{\circ} \mathrm{C}, 80 \mathrm{rpm}$, for 3 hours) to produce a suspension bacteria.

Spores from the $B$. thuringiensis subsp. aizawai strain ABTS- 1857 was retrieved from the same insecticide as cited above (Xentari WG, Bayer CropScience SA-NV, Belgium). For each experiment, a fresh suspension of the Xentari powder was diluted and spiked on the surfaces, immediately before the reading.

The genus Cladosporium, found worldwide, is the most common outdoor and indoor environmental fungus. Different species, particularly Cladosporium herbarum, produce very high concentrations of airborne conidia (asexually produced spores) responsible of respiratory allergies [14]. The strain C. herbarum CTMA/189, which was isolated from the air in Belgium in 2008, was grown 8 days on agar slant (modified Sabouraud medium) in order to obtain an abundant production of aerial conidia. Tris-buffered saline (TBS) solution with 2 drops of Tween 80 was added to the slant, and conidia were liberated into the liquid by scrapping the surface of the colony. The conidia suspension was pipetted and placed inside a $15 \mathrm{~mL}$ Falcon tube (stock solution).

The bacteriophage MS2, a small-sized icosahedral RNA virus commonly used as a simulant for pathogenic viruses in a large number of studies, was produced as previously described by Bentahir $\mathrm{M}$, et al. $[15,16]$. The MS2 viral titre of the cell lysate was determined by culture method using the double agar overlay phage assay (DAL) [17]. The MS2 stock solution is at $1.24 \times 10^{10} \mathrm{PFU} / \mathrm{mL}$.

\section{Testing for surface contamination and monitoring decontamination kinetics}

Each bacterial, viral or fungal sample was diluted to a predefined concentration. The liquid sample containing the biological contaminant $(10 \mathrm{~mL})$ was spread on an $8 \times 11 \mathrm{~cm}$ area of the horizontal copper surface to form a wet area of $\sim 100 \mathrm{~cm}^{2}$ as the target surface hit by the laser beam. The reading was carried out as described above under paragraph "Principles of use of the BC-Sense device". While LIDAR measurements were all carried out with biological agent suspensions, replicated measurements on dried contaminated surfaces (i.e., surfaces let to dry after deposition of the microbial contaminated solution) did not change the recorded spectrum. Considering the time for surfaces to dry and the number of experiments, it was therefore decided for very practical reasons to pursue the work on wet surfaces and to carry out the measurements shortly after spreading a sample on a surface.

The linearity of the measures was tested by a serial dilution of $E$. coli and MS2 bacteriophage in a water-based solution. Data were used to construct a calibration curve in order to accurately calculate the limits of detection (LoD) and quantification (LoQ) of both agents. The $\mathrm{LoQ}$, which is set at a higher concentration than the LoD, is the lowest concentration at which the analyte can not only be reliably detected but at which some predefined goals for bias and imprecision are met [18]. LoD and LoQ are two important values for assessing sensitivity and performance characteristics in a validation trial.

Different concentrations $(\mathrm{n}=5)$ and several replicates measurements $(n=4)$ were used for building the calibration curve. Samples were prepared by diluting the stock solution of living E. coli and MS2 bacteriophage virus by tenfold serial dilutions to find the concentration where the signal to noise ratio was low enough so that the spectrum of the biological agent was barely higher than the noise.

For testing the effect of decontamination, $0.5 \%$ sodium hypochlorite (bleach) solution was freshly prepared by diluting an anhydrous sodium dichloroisocyanurate $(\mathrm{NaDCC})$ powder (Melspring International b.v., the Netherlands) in water before the measurement. The suspension containing the biological contaminant was spread on the copper surface and mixed with $10 \mathrm{ml}$ of $0.5 \%$ chlorine solution. The dynamic of the decontamination process was then monitored by realtime measurement of the decrease in output fluorescence from agent proteins.

\section{Selection of a set of representative solid surfaces}

A panel of surface materials frequently exposed to biological contamination in real-life incidents or situations were selected for use during the contamination and decontamination assessment, i.e., laboratory coat, wood, Plexiglas/PMMA [poly (methyl methacrylate)], glass, galvanized steel, aluminium, rigid PVC and a UV-resistant PVC fabric. The latter is a piece of the canvas tent from the B-LiFE deployable laboratory of CTMA-UCL [19]. Each material was cut to have a rectangular shape of $8 \mathrm{~cm}$ wide and $11 \mathrm{~cm}$ long. BC-Sense testing was carried out on the surface of the material placed on the top of the copper surface. The intrinsic fluorescence from each type of surface was assessed before spreading the biological agents (i.e., bacteria, spores, fungal conidia and virus) (Figure 2). 
Citation: Babichenko S, Bentahir M, Piette AS, Poryvkina L, Rebane O, et al. (2018) Non-Contact, Real-Time Laser-Induced Fluorescence Detection and Monitoring of Microbial Contaminants on Solid Surfaces Before, During and After Decontamination. J Biosens Bioelectron 9: 255. doi: $10.4172 / 2155-6210.1000255$

Page 4 of 9
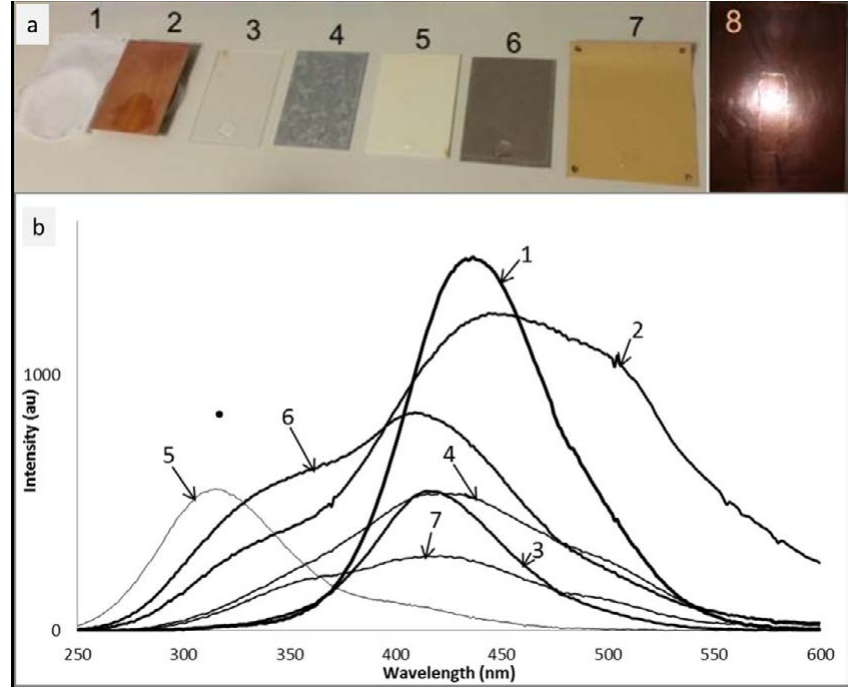

Figure 2: Background fluorescence of solid surfaces. (a) Set of representative solid surfaces used for microbial contamination: 1 - cloth of lab coat, 2 - wood, 3 -Plexiglas/PMMA (poly(methyl methacrylate)), 4 galvanized steel, 5 - PVC plastic, 6 - aluminium, 7 - canvas tent , 8 - copper plate. (b) Corresponding gain-normalized LIF spectra of solid surfaces at the excitation $248 \mathrm{~nm}$ : spectrum of white lab coat (1) is divided by 100; spectrum of PVC (5) is divided by 10; copper plate (8) provided no fluorescence.

\section{Spectral analysis of microbial contaminated suspensions deposited on solid surfaces}

The LIF spectra of each component of the microbial solution (i.e., microbial agents, PBS and TBS solutions, and growth media) and clean versus contaminated surfaces have been measured to compile a global data set for building the BC-Sense classifier. The goal was to use the classifier to enable operator to distinguish a contaminated from a clean or completely decontaminated surface, irrespective of the arbitrary combination of surfaces and microbial contaminants. Due to a limited training dataset, an ensemble learning strategy, namely Bootstrap aggregation, was applied in order to discriminate among different types of biological contamination and surfaces. Wavelet feature extraction and selection was also used prior to application of the analysis algorithm, as previously reported [20-22].

\section{Results}

\section{Intrinsic fluorescence of surface materials}

Before carrying out RTDM on contaminated surfaces, the intrinsic fluorescence of each uncontaminated counterpart was measured and the corresponding LIF spectra were taken as a reference. All fluorescence spectra using an excitation wavelength of $248 \mathrm{~nm}$ covered a spectral range between 380 and $520 \mathrm{~nm}$ with main fluorescence bands appearing beyond $400 \mathrm{~nm}$, with the notable exception of the band corresponding to PVC plastic which produced a fluorescence peak at $310 \mathrm{~nm}$. The LIF spectra showed major variations between two extremes: as desired, the copper plate produced no fluorescence signal whereas lab coat and PVC plastic produced the highest peaks, being 100 and 10 times higher than other materials, respectively. These recoded LIF spectra constituted the reference data set of spectral backgrounds which could be used as a comparison with fluorescence signals produced by microbial contaminated surfaces.

\section{Microbial contaminants fluorescence using a non-fluorescent solid support}

The LIF spectra of microbial contaminants were measured with the samples placed on the copper plate. As no fluorescence is generated by copper (cf supra, Intrinsic fluorescence of surface materials), each spectrum was considered to exclusively result from the microbial contaminant solution. The LIF data recorded with various microbial samples revealed similarities and differences.

With an excitation wavelength of $248 \mathrm{~nm}$, bacterial models produced maximal fluorescence intensity at $330 \mathrm{~nm}$, attributed to tryptophan [7]. The spectra characterizing Bacillus spores, C. herbarum conidia and MS2 bacteriophage differed markedly from bacterial spectra. The fluorescence maxima were observed at 410, 360 and $430 \mathrm{~nm}$, respectively, and are therefore easily distinguishable. At the excitation wavelength of $248 \mathrm{~nm}$, dead and living $E$. coli bacteria had a similar LIF spectral shape. The fluorescence spectrum of dead E. coli exhibited a shoulder near $450 \mathrm{~nm}$ and higher fluorescence intensity compared to living E. coli and B. thuringiensis (Figure 3).

At the excitation wavelength of $351 \mathrm{~nm}$, the LIF spectrum of dead $E$. coli contained noticeable fluorescence in the spectral range of 400-500 nm, not seen with living counterparts an attributed to NADH (Figure 4) $(23,24)$.

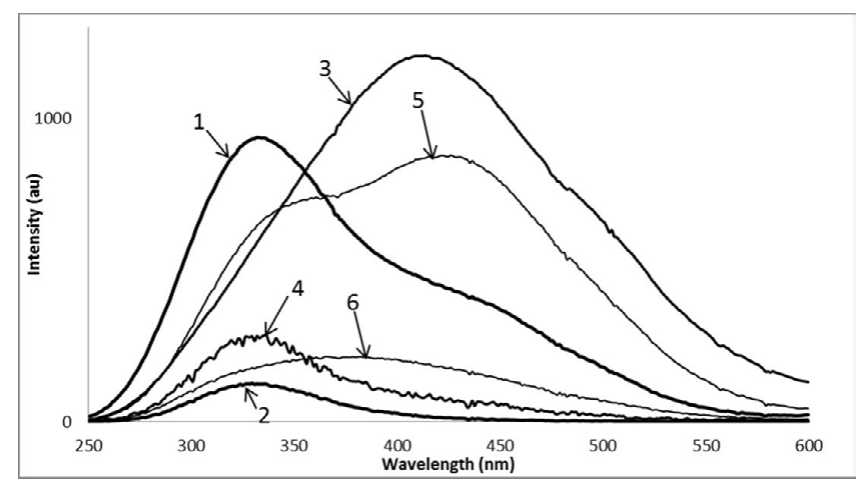

Figure 3: LIF spectra of biological contaminants at the excitation wavelength of $248 \mathrm{~nm}$

1 - E. coli (dead bacteria) 6×1010 CFU/ml, 2 - E. coli (living bacteria) $1 \times 10^{7}$ $\mathrm{CFU} / \mathrm{ml}, 3-$ Bacillus spores $5 \mathrm{~g} / \mathrm{ml}, 4-\mathrm{B}$. thuringiensis $2 \times 10^{8} \mathrm{CFU} / \mathrm{ml}$ (signal multiplied by 10 for visibility), 5 - MS2 Virus $1 \times 10^{9} \mathrm{PFU} / \mathrm{ml}, 6-$ Cladosporium herbarum (unknown concentration).

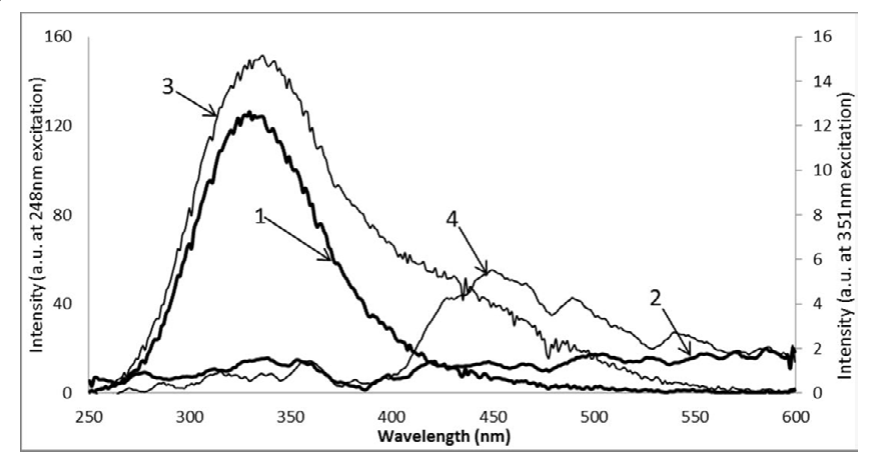

Figure 4: LIF spectra of living and dead bacteria $E$. coli

1 - living E. coli excited at $248 \mathrm{~nm}, 2$ - living E. coli excited at $351 \mathrm{~nm}, 3$ - dead E. coli excited at $248 \mathrm{~nm}, 4-$ dead $E$. coli excited at $351 \mathrm{~nm}$. 
Citation: Babichenko S, Bentahir M, Piette AS, Poryvkina L, Rebane O, et al. (2018) Non-Contact, Real-Time Laser-Induced Fluorescence Detection and Monitoring of Microbial Contaminants on Solid Surfaces Before, During and After Decontamination. J Biosens Bioelectron 9: 255. doi: $10.4172 / 2155-6210.1000255$

Page 5 of 9

LoD calculated using LIF calibration curves for E. coli bacteria and the MS2 virus were $2.9 \times 10^{4}$ and $9.5 \times 10^{4} \mathrm{CFU} / \mathrm{cm}^{2}$, respectively. The LoQ values were $3.4 \times 10^{5}$ and $10^{6} \mathrm{PFU} / \mathrm{cm}^{2}$ for living E. coli and MS2 bacteriophage virus, respectively (Table 1).

\section{Spectral analysis of microbial contaminants on solid surfaces}

The total set of LIF spectra collected during the experiment consisted of more than 800 samples measured in replicates. The training dataset for the classifier consisted of 101 spectra of E. coli and MS2 contaminants and of a panel set of microbial-uncontaminated solid surfaces $(n=85)$ with their respective fluorescence. The training dataset "out-of-bag" error was 0.08 . The LIF spectra of bacterial spores and fungal conidia were not included in the training dataset but used in the test data set. The test dataset consisted of 628 samples, with 37 false and 47 unknown results.

The classifier was created as detailed above (cf the "spectral analysis of microbial contaminated solution on solid surfaces") and embedded into RTDM procedure of the BC-Sense device. When a LIF spectrum was recorded by the $\mathrm{BC}$-Sense, the classifier instantly produced the value of predicted response (PR) ranging from 0 (lack of contamination) to 1 (100\% probability of contamination).

Random samples ( $n=200)$ were assessed. For the clarity of resulting visualization, the $\mathrm{PR}$ of the classifier distributed in four different groups based on LIF spectra. Group I presented the data recorded with a panel of uncontaminated surface materials: PR was consistently $<0.25$, according to the classifier. Group II included E. coli on various surfaces versus solvents: PR was $>0.6$ and $<0.3$, respectively. Group III presented the LIF data recorded with MS2 virus on various surfaces versus culture media used for bacterial and viral growth: $P R$ was $>0.6$ and $<0.2$, respectively. Group IV included the LIF spectra generated by bleach alone versus bacterial spores and fungal conidia contaminated solid surfaces. In this group, the classifier discriminated contaminated surfaces $(\mathrm{PR}>0.6)$ from bleach $(\mathrm{PR}<0.2)$.

Data analysis with respect to PR showed that two thresholds discriminate between contamination and background signals: $<0.4$ considered as negative whereas $>0.55$ being considered contaminated.

BC-sense analysis of solvents, growth media, and solid surfaces with and without microbial contaminants: data mining and result analysis. The predicted response (PR) of the $\mathrm{BC}$-sense classifier for 200 random samples of solvents, growth media, and solid surfaces with and without microbial contaminants: group I - PR $<0.25$ for clean surfaces; group II - PR $<0.3$ for solvents and $\mathrm{PR}<0.6$ for the surfaces contaminated by $E$. coli; group III $-\mathrm{PR}<0.2$ for media samples and $\mathrm{PR}>0.6$ for the surfaces contaminated by MS2 virus; group IV $-\mathrm{PR}<0.2$ for the bleach and $\mathrm{PR}$ $>0.6$ for bacterial spores and fungal conidia. Blank markers and thin noughts below $0.45 \mathrm{PR}$ represent pure background materials, nutrient solutions and blank, felled markers and bold noughts above $0.55 \mathrm{PR}$ represent cultures of microorganisms and materials contaminated by them. The legend shows more details on the type of the surface and contamination.

As expected, the classifier was not able to detect contamination when surface contamination was carried out with a microbial concentration near the LoD of the BC-Sense tool (Table 1). The spectral shape and intensity of fluorescence of background surfaces influenced the detection capability. In particular, $E$. coli was correctly detected by the classifier on PVC, canvas tent and aluminium, while its detection on Plexiglas/PMMA and galvanized steel was challenging. In the latter case, the detection reliability depended indeed on the bacterial concentration. The MS2 virus was successfully detected on Plexiglas/ PMMA, canvas tent, PVC, aluminium and steel. As described above uncontaminated background materials, solvents and growth media were always correctly discriminated by classifier (Figure 5 ).

Light Induced Fluorescence (LIF) and Spectral Fluorescence Signatures (SFS) or "spectral fingerprinting" were successfully tested in near-real life condition in the B-LiFE laboratory tent in Bologna during the large-scale "food defence" demonstration in April 2016 in the framework of the Seven framework European project EDEN (Enduser driven Demo for cbrN) [23-25]. The demonstration focused on deliberate food contamination with a norovirus in a meat production facility. Both techniques correctly identified contaminated slices of the mortadella-type sausage (Figure 6).

\section{Online RTDM during the decontamination process}

BC-Sense LIDAR device was finally used to monitor in real-time the kinetics of decontamination when treating contaminated surfaces by bleach. The decontamination efficiency, expressed as a decrease in fluorescence intensity, was assessed on surfaces contaminated with living E. coli cells, MS2 bacteriophage and spores of B. thuringiensis.

The dynamic decrease in fluorescence intensity was monitored in real-time on the corresponding LIF spectra. Pouring $0.5 \%$ chlorine solution directly onto a microbial-contaminated surface generated indeed an immediate and abrupt drop of fluorescence. With MS2, a complete disappearance of the fluorescence was achieved in 1 minute whereas this lasted longer (up to $10 \mathrm{~min}$ ) with $E$. coli and spores of $B$. thuringiensis (Figure 7).

\section{Discussion and Conclusions}

Various methods are currently used in the detection of microbiological contamination on surfaces, e.g., ATP-bioluminescence assay, PCR-based methods and a large variety of optical methods $[23,24,26]$. Most of them, especially nucleic acid- and antibody-based assays, are cumbersome, expensive and require a long turnaround time. Before the analytical step, samples need first to be collected from targeted surfaces before undergoing adequate processing. ATPbioluminescence assay requires preliminary surface preparation with specific antibodies, hence providing at best questionable results, whereas other assays require rather complex analysis of collected samples.

Global issues related to surface contamination, and detection thereof, were clearly evidenced during the last Ebola outbreak in West Africa. They perfectly illustrate the current technological challenges. During this outbreak, the risk of nosocomial transmission through indirect Ebola virus (EBOV) transmission via surfaces or fomites contaminated with the patient's blood or body fluids was a daily concern. Whilst the incidence of nosocomial infection within Ebola

\begin{tabular}{|c|c|c|c|c|c|c|c|c|}
\hline Microorganism & LoD & LoQ & RSD \% & $\mathbf{R}^{2}$ & Linearity & Range & Recovery \% & Units \\
\hline E. coli (living bacteria) & $2.85 \mathrm{E} 4$ & 9.49E4 & 6.21 & 0.9963 & $8 \mathrm{E} 4-8 \mathrm{E} 5$ & $9 \mathrm{E} 4-8 \mathrm{E} 5$ & 103.00 & $\mathrm{CFU} / \mathrm{cm}^{2}$ \\
\hline MS2 virus & 3.36E5 & 1.12E6 & 10.97 & 0.9736 & 4E5 - 4E6 & 1E6 -4E6 & 99.00 & $\mathrm{PFU} / \mathrm{cm}^{2}$ \\
\hline
\end{tabular}

Table 1: Limits of Detection (LOD) and Quantification (LOQ) of the experimental setup. 
Citation: Babichenko S, Bentahir M, Piette AS, Poryvkina L, Rebane O, et al. (2018) Non-Contact, Real-Time Laser-Induced Fluorescence Detection and Monitoring of Microbial Contaminants on Solid Surfaces Before, During and After Decontamination. J Biosens Bioelectron 9: 255. doi: $10.4172 / 2155-6210.1000255$

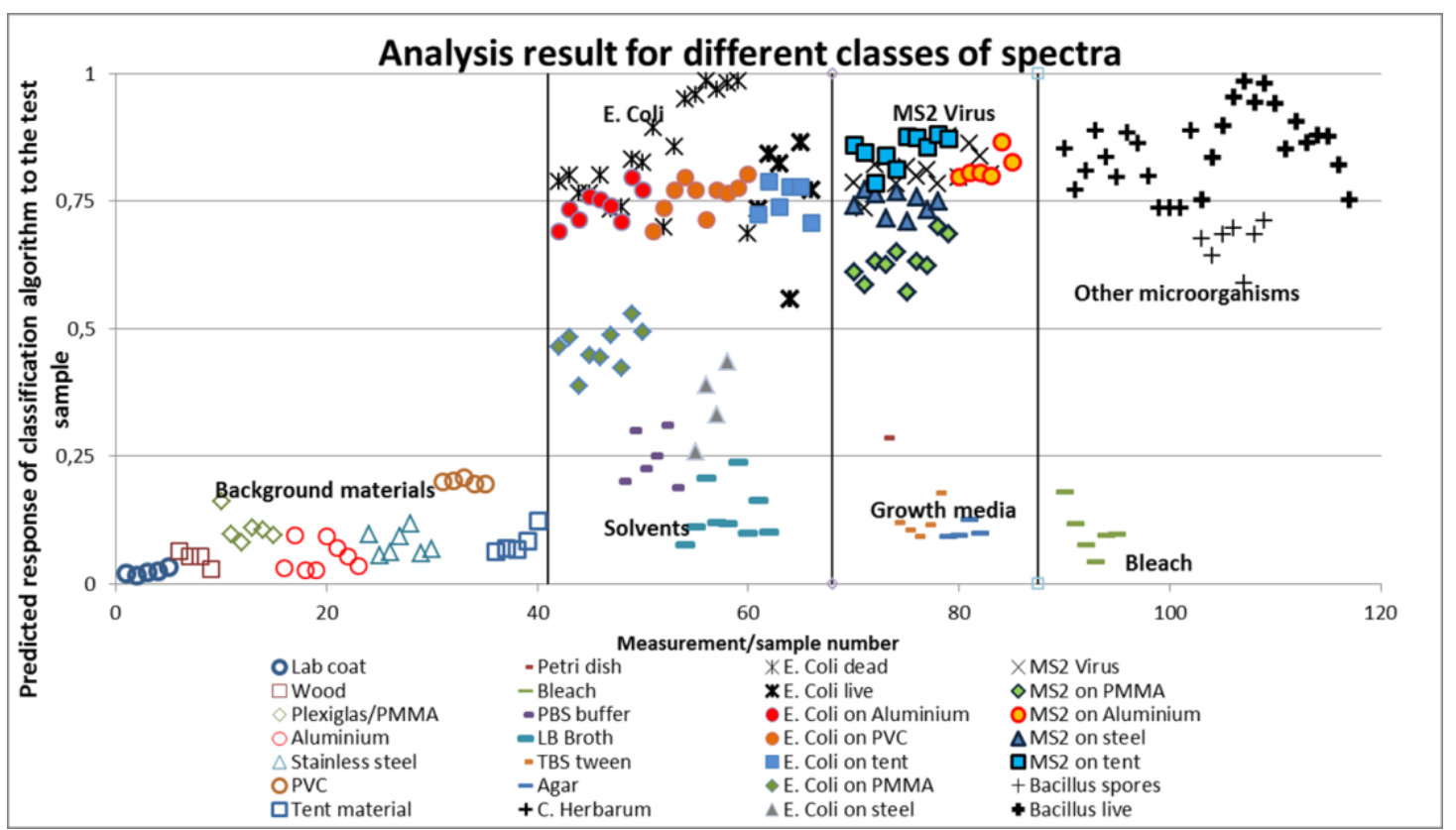

Figure 5: Analysis result for different classes of spectra

BC-sense analysis of solvents, growth media, and solid surfaces with and without microbial contaminants: data mining and result analysis. The predicted response (PR) of the BC-sense classifier for 200 random samples of solvents, growth media, and solid surfaces with and without microbial contaminants: group I - PR < 0.25 for clean surfaces; group II - PR $<0.3$ for solvents and PR $<0.6$ for the surfaces contaminated by E. coli; group III - PR $<0.2$ for media samples and PR $>$ 0.6 for the surfaces contaminated by MS2 virus; group IV - PR $<0.2$ for the bleach and PR $>0.6$ for bacterial spores and fungal conidia. Blank markers and thin noughts below 0.45 PR represent pure background materials, nutrient solutions and blank, felled markers and bold noughts above 0.55 PR represent cultures of microorganisms and materials contaminated by them. The legend shows more details on the type of the surface and contamination.

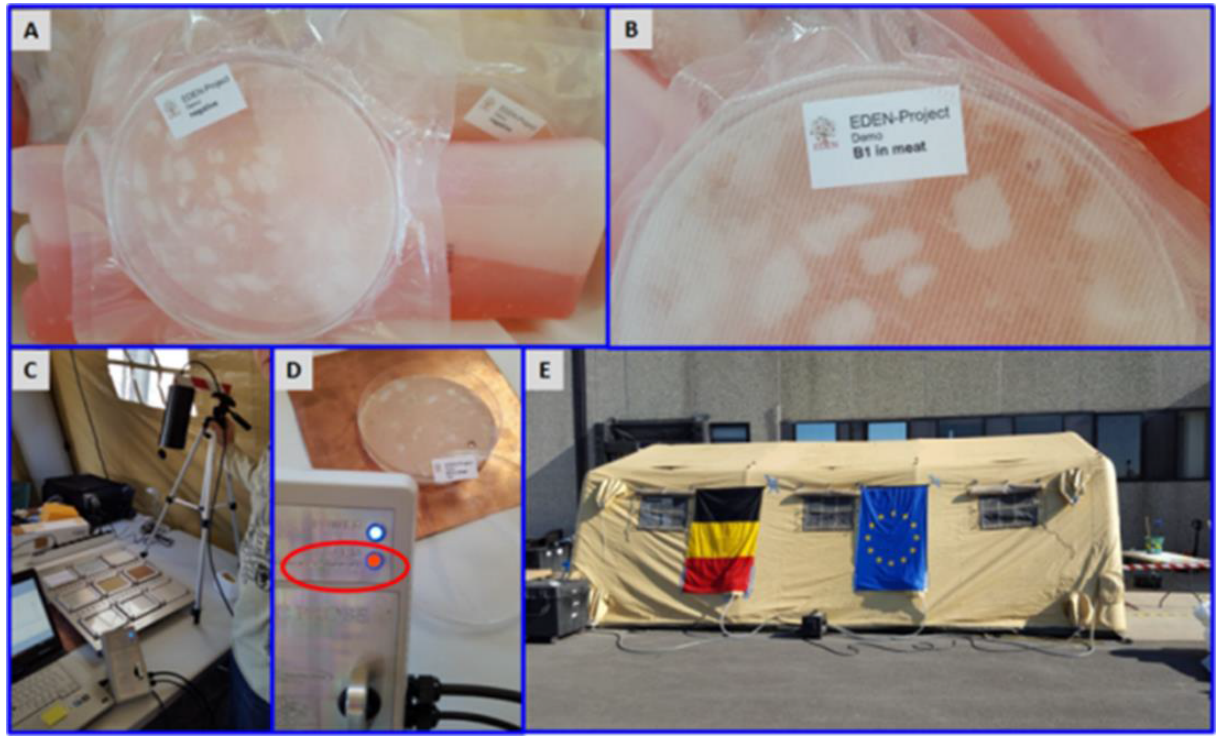

Figure 6: RTDM of slices of the mortadella-type sausage using BC-Sense in a laboratory tent (Bologna, April 2016, FP7-EDEN, large-scale Food Defence demonstration). EDEN demonstration scenario: Food contamination (norovirus) in a meat production facility. (A)Slice non contaminated used as negative control; (B) B1 meat sample: the surface of the slice was contaminated with a norovirus; (C) Simplified portable version of BC-Sense; (D) Positive signal from a contaminated slice; (E) B-LiFE Laboratory tent hosting the BC-Sense during the EDEN demonstration.

healthcare facilities remains contentious, several contaminations indeed occurred in health care workers (HCWs) regardless of strict infection prevention and control measures. This outlined the need to improve the understanding of the EBOV environmental transmission, i.e., how long and where does the virus survive in real life conditions and whether it withstands current decontamination protocols. Accordingly, surface swabbing followed by EBOV-specific RNA-based assay was proposed to assess viral persistence in the immediate vicinity 

and Monitoring of Microbial Contaminants on Solid Surfaces Before, During and After Decontamination. J Biosens Bioelectron 9: 255. doi: $10.4172 / 2155-6210.1000255$

Page 7 of 9

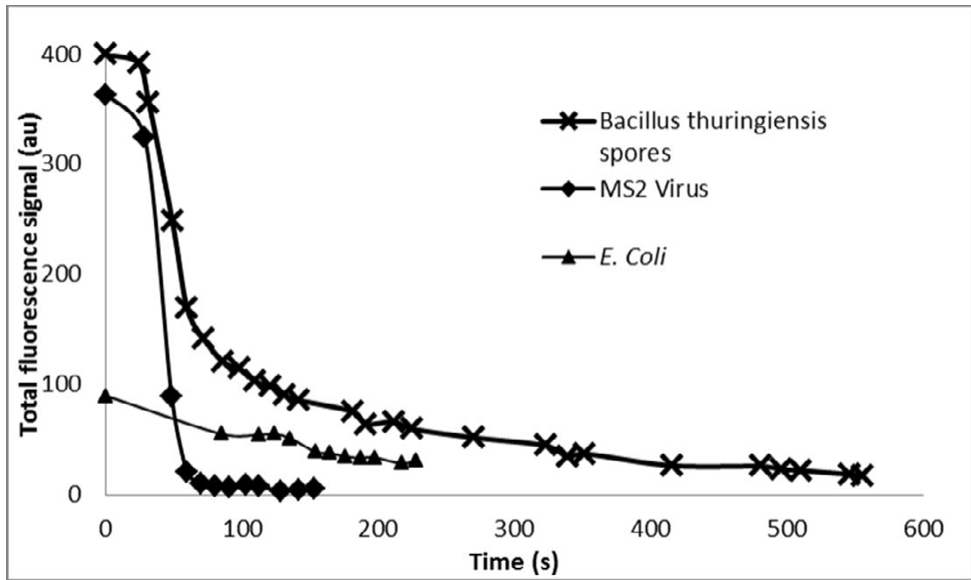

Figure 7: Bleach decontamination kinetics. Decrease of integral fluorescence signal, in the spectral range $250 \mathrm{~nm}$ to $600 \mathrm{~nm}$, during microbia decontamination of Bacillus spores, MS2 bacteriophages and E.coli due to surface decontamination with $0.5 \%$ sodium hypochlorite solution.

of Ebola patients, namely on material in contact with patients like beds, mattresses and linens, as well as on HCWs personal protective equipment and gloves [27-31]. Results demonstrated the relatively high stability of viral RNA, especially in high temperatures and moisty conditions, as is the case in tropical settings. In addition to this, there was mounting evidence that EBOV can remain viable on surfaces for several days under simulated environmental conditions for the climate of West Africa [32]. Altogether, these results advocated the detection of EBOV RNA as a surrogate marker of viral contamination of the environment and its use as the most sensitive measure of safety. Nucleic acid-based assay appeared to be the best and only method for residual hazard assessment, i.e., complete versus incomplete decontamination according to whether RNA disappears or not. Nevertheless, due to biosafety and regulatory issues, none of the above studies could carry out viral culture in the field, in real operational conditions, nor could samples be exported abroad for confirmatory testing [28,30,31]. Consequently, genuine study limitations such as lack of confirmation of the viability and infectivity of EBOV from RNA positive specimens tempered the interpretation of RNA-based results. Moreover, it should not be overlooked that EBOV culture can produce false-negative results with the swabbing method, especially when the microbial load is low, hence making questionable the reliability of a negative viral culture from RNA EBOV positive samples [27,33].

Interestingly enough, constraints and issues associated with potential microbial surface contamination extend far beyond the Ebola case. Indeed, swabs and wipes followed by sample processing have long been applied in different fields among which medical applications, food safety and biothreat assessment [34-40]. However, a series of limitations strongly affect this type of safety control protocol among which a sizebiased sampling, the type of sampling field, the nature of environmental swab samples which makes the use of multiple swabs on the same site impossible, and the use of different collection and analytical methods limiting their applicability to the real world setting. Consequently, sampling inconsistency cannot be ruled out and technique variability in sample collection may be responsible for discordant results. Besides, swabbing does not always lend itself to use with life-threatening agents owing to biosafety concerns during processing.

Therefore, evidence-based decontamination procedures should protect those at risk of contamination from environmental sources (hospitalized patients, hospital staff, population....) or from intentional release of biological agents using field-based tools that can serve as surrogate measures of viable or dead microbial agents on surfaces, without neither sampling nor acid nucleic-based analysis. So far, only scarce data report on methods that allow RTDM of microbial contaminants, mainly for medical or food applications [41-43]. The LIF method with a dual wavelength sensing and multispectral pattern recognition enables BC-sense LIDAR a non-contact detection based on the primary component analysis of intrinsic fluorescence spectra of biological models [4]. According to current results, spectral shapes allowed distinguishing between groups of biological agents and background (e.g., culture medium, solvents and surface material) while minimizing false-positive results [22]. A panel of microbial agents on a range of solid surfaces were correctly classified without sample collection or analytical procedure and with a turnaround time $<3$ seconds for each identification test. A consistent discrimination of contaminated versus non-contaminated surfaces was possible using optimal thresholds as defined here, i.e., $P R>0.55$ as indicator of surface contamination and $\mathrm{PR}<0.4$ for surface cleanliness. Provisional identification of the group of biological agent was obtained by using a robust decision tree-learning algorithm that compared the fluorescence spectra of unknown microbial contaminants with a database of $>800$ samples collected during this study.

The fluorescence maximum peak of bacteria excited at $248 \mathrm{~nm}$ is attributable to tryptophan fluorescence. The fluorescence spectra of dead and living E. coli looked comparable except at $351 \mathrm{~nm}$ excitation where the difference was supposedly related to $\mathrm{NADH}$ fluorescence. In some studies, NADH fluorescence is indeed used as biomarker of cell viability and/or cell death $[10,44,45]$. NADH expression increases after induction of cell injury or death and decreases until cell death, making it an interesting marker to discriminate between alive and dead bacterial cells. In line with previous reports, bacillus spores, MS2 bacteriophage and C. herbarum conidia showed different spectra compared with bacteria, which make them easily recognizable [46,47]. The fluorescence of bacteriophage MS2 is attributed to the tyrosine in the coat protein $[48,49]$. While the most efficient spectral range to excite the fluorescence of tyrosine is $275-300 \mathrm{~nm}$, the sensing wavelength $248 \mathrm{~nm}$ of BC-Sense induced its noticeable fluorescence as well. Viral LIF spectra showed two peaks, the highest being around 430 $\mathrm{nm}$, suggesting that this part of the spectra may be influenced by $E$. coli lysate (dead cells) following viral replication [47]. Anyhow, the viral 
Citation: Babichenko S, Bentahir M, Piette AS, Poryvkina L, Rebane O, et al. (2018) Non-Contact, Real-Time Laser-Induced Fluorescence Detection and Monitoring of Microbial Contaminants on Solid Surfaces Before, During and After Decontamination. J Biosens Bioelectron 9: 255. doi: $10.4172 / 2155-6210.1000255$

Page 8 of 9

spectrum differs from both alive and dead bacteria spectra, outlining the ability of BC-Sense to identify the type of biological contamination. It is also noteworthy that current detection and quantification limits, evaluated with live E. coli and MS2, are relatively high and should be improved. Nevertheless, results are promising. Further technological developments combined with database enrichment with fluorescence spectra from additional biological models and background material will undoubtedly improve the limit of detection and quantification.

Regarding surface decontamination, the most common cleaning fluid used is a chlorine solution (bleach). The primary decontamination effect occurs because hypochlorite anions oxidize and denature the large three-dimensional structure of proteins, opening them up and altering the amino acids which lie inside [50]. The chlorine solution destroys the biomolecules in time scale from seconds to minutes depending on the type of microorganisms. The BC-Sense tool enabled operators to follow in real-time the decontamination kinetics of the chlorine treatment using biological models with varying bleach sensitivity (e.g., virus more sensitive than spores). The monitoring of cleaning efficiency, using different decontamination solutions on an extensive panel of biological agents (e.g., spore, viruses, bacteria and toxins) and surfaces (porous versus non-porous material), will help optimize decontamination protocols and methods. This is also very much needed, knowing that bleach may cause serious damage to equipment used in a contaminated environment [19].

In conclusion, the BC-Sense LIDAR device was developed, using the LIF method based on dual wavelength sensing with multispectral pattern recognition system, enabling operators a user-friendly RTDM of microbial contamination/decontamination on solid surfaces. This device has a high positive impact in terms of biosafety as it provides first responders with a better situational awareness without the manipulation and transport of potentially dangerous samples, hence limiting personal exposure to biological agents and the risk of spreading the contamination. A quick determination of the extent and nature of a suspected microbial contamination without sampling is paramount for risk assessment and decision making on sample collection in appropriate biosafety conditions (i.e., level of protective equipment and standard operating procedures for sampling and safe packaging). This tool fills therefore a major gap in real-time assessment of biological hazard in work environment, residual hazard assessment after decontamination (i.e., decontamination efficiency), and guidance for the type and thoroughness of cleaning procedures.

\section{Acknowledgement}

This work has received funding from the European Union Seventh Framework Programme (FP7/2007-2013), theme security (SEC), FP7-SEC EDEN project (End-user driven Demo for cbrNe) under the Grant no. 313077. The funding source had no involvement in the research design and development.

\section{References}

1. Piette AS, Vybornova O, Bentahir M, Gala JL (2014) CBRN: Detection and identification innovations. Crisis Response Journal 10: 36-38.

2. Medema J (2009) How clean is clean enough? CBRNe WORLD. Autumn pp: 68-70.

3. Hausmann A, Duschek F, Fischbach T, Pargmann C, Aleksejev V, et al. (2014) Standoff detection: Classification of biological aerosols using laser induced fluorescence (LIF) technique. Environmental and Industrial Sensing.

4. Sohn M, Himmelsbach DS, Barton FE, Fedorka-Cray PJ (2009) Fluorescence spectroscopy for rapid detection and classification of bacterial pathogens. Appl Spectrosc 63: 1251-1255.

5. Sedlacek AJ, Ray MD, Higdon NS, Richter DA (2002) Short-range noncontact detection of surface contamination using Raman lidar. Vibrational Spectroscopy- based Sensor Systems; 2002: International Society for Optics and Photonics.

6. Multari RA, Cremers DA, Dupre JAM, Gustafson JE (2013) Detection of biological contaminants on foods and food surfaces using laser-induced breakdown spectroscopy (LIBS). J Agric Food Chem 61: 8687-8694.

7. Tao F, Peng Y, Li Y, Chao K, Dhakal S (2012) Simultaneous determination of tenderness and Escherichia coli contamination of pork using hyperspectral scattering technique. Meat Science 90: 851-857.

8. Ghisaidoobe AB, Chung SJ (2014) Intrinsic tryptophan fluorescence in the detection and analysis of proteins: A focus on Forster resonance energy transfer techniques. Int J Mol Sci 15: 22518-22538.

9. Nevin A, Cather S, Anglos D, Fotakis C (2006) Analysis of protein-based binding media found in paintings using laser induced fluorescence spectroscopy. Anal Chim Acta 573: 341-346.

10. Liang J, Wu WL, Liu ZH, Mei YJ, Cai RX, et al. (2007) Study the oxidative injury of yeast cells by NADH autofluorescence. Spectrochim Acta A Mol Biomol Spectrosc 67: 355-359

11. Cooper GM, Hausman RE (2000) The cell: Sinauer Associates Sunderland.

12. Harwood CR (2007) Bacillus subtilis as a Model for Bacterial Systems Biology Wiley Online Library.

13. Greenberg DL, Busch JD, Keim P, Wagner DM (2010) Identifying experimental surrogates for Bacillus anthracis spores: a review. Investig Genet 1: 4.

14. Schubert K, Groenewald J, Braun U, Dijksterhuis J, Starink M, et al. (2007) Biodiversity in the Cladosporium herbarum complex (Davidiellaceae Capnodiales), with standardisation of methods for Cladosporium taxonomy and diagnostics. Stud Mycol 58: 105-156.

15. O'Connell KP, Bucher JR, Anderson PE, Cao CJ, Khan AS, et al. (2006) Real-time fluorogenic reverse transcription-PCR assays for detection of bacteriophage MS2. Appl Environ Microbiol 72: 478-483.

16. Bentahir M, Laduron F, Irenge L, Ambroise J, Gala JL (2014) Rapid and Efficient Filtration-Based Procedure for Separation and Safe Analysis of CBRN Mixed Samples. PLoS One 9: e88055

17. Kropinski AM, Mazzocco A, Waddell TE, Lingohr E, Johnson RP (2009) Enumeration of bacteriophages by double agar overlay plaque assay. Bacteriophages Methods Mol Biol 501: 69-76.

18. Armbruster DA, Pry T (2008) Limit of blank, limit of detection and limit of quantitation. Clin Biochem Rev 29: S49-S52.

19. Irenge LM, Dindart JM, Gala JL (2017) Biochemical testing in a laboratory tent and semi-intensive care of Ebola patients on-site in a remote part of Guinea: a paradigm shift based on a bleach-sensitive point-of-care device. Clin Chem Lab Med 55: 1881-1890.

20. Breiman L (1996) Bagging predictors. Machine learning 24: 123-140.

21. Breiman L (2001) Random forests. Machine learning 45: 5-32.

22. Sobolev I, Babichenko S (2013) Application of the wavelet transform for feature extraction in the analysis of hyperspectral laser-induced fluorescence data. Int J Remote Sens 34: 7218-7235.

23. Aiken ZA, Wilson M, Pratten J (2011) Evaluation of ATP bioluminescence assays for potential use in a hospital setting. Infection Control \& Hospital Epidemiology 32: 507-509.

24. Talkington DF (2013) PCR Detection of Microbial Pathogens. Emerging Infect Dis 19: 1353.

25. Vybornova O, Vybornova O, Gala JL, Gala JL (2016) Decision support in a fieldable laboratory management during an epidemic outbreak of disease. Journal of Humanitarian Logistics and Supply Chain Management 6: 264-295.

26. Fischer M, Triggs G, Krauss TF (2016) Optical sensing of microbial life on surfaces. Appl Environ Microbiol 82: 1362-1371.

27. Bausch DG, Towner JS, Dowell SF, Kaducu F, Lukwiya M, et al. (2007) Assessment of the risk of Ebola virus transmission from bodily fluids and fomites. J Infect Dis 196: 142-147.

28. Youkee D, Brown CS, Lilburn P, Shetty N, Brooks T, et al. (2015) Assessment of environmental contamination and environmental decontamination practices within an ebola holding unit, Freetown, Sierra Leone. PloS one 10: e0145167. 
Citation: Babichenko S, Bentahir M, Piette AS, Poryvkina L, Rebane O, et al. (2018) Non-Contact, Real-Time Laser-Induced Fluorescence Detection and Monitoring of Microbial Contaminants on Solid Surfaces Before, During and After Decontamination. J Biosens Bioelectron 9: 255. doi: $10.4172 / 2155-6210.1000255$

29. Cook BW, Cutts TA, Nikiforuk AM, Poliquin PG, Strong JE, et al. (2015) Evaluating environmental persistence and disinfection of the Ebola virus Makona variant. Viruses 7: 1975-1986.

30. Poliquin PG, Vogt F, Kasztura M, Leung A, Deschambault Y, et al. (2016) Environmental contamination and persistence of Ebola virus RNA in an Ebola treatment center. J Infect Dis 214: 145-152.

31. Palich R, Irenge LM, De Sainte Fare EB, Augier A, Malvy D, et al. (2017) Ebola virus RNA detection on fomites in close proximity to confirmed Ebola patients; N'Zerekore, Guinea, 2015. PloS one 12: 1-10.

32. Fischer R, Judson S, Miazgowicz K, Bushmaker T, Prescott J, et al. (2015) Ebola virus stability on surfaces and in fluids in simulated outbreak environments. Emerg Infect Dis 21: 1243-1246.

33. Spengler JR, McElroy AK, Harmon JR, Ströher U, Nichol ST, et al. (2015) Relationship between Ebola virus real-time quantitative polymerase chain reaction-based threshold cycle value and virus isolation from human plasma. $\mathrm{J}$ Infect Dis 212: 346-349.

34. Kovach CR, Taneli Y, Neiman T, Dyer EM, Arzaga AJA, et al. (2017) Evaluation of an ultraviolet room disinfection protocol to decrease nursing home microbial burden, infection and hospitalization rates. BMC Infect Dis 17: 186.

35. Varona-Barquin A, Ballesteros-Peña S, Lorrio-Palomino S, Ezpeleta G, Zamanillo V, Eraso E, et al. (2017) Detection and characterization of surface microbial contamination in emergency ambulances. Am J Infect Control 45: 69-71.

36. Ronnqvist M, Ratto M, Tuominen P, Salo S, Maunula L (2013) Swabs as a too for monitoring the presence of norovirus on environmental surfaces in the food industry. J Food Prot 76: 1421-1428.

37. Patel D, Stansell J, Jaimes M, Ferris K, Webb G (2017) A Survey of Microbial Contamination on Restaurant Nonfood-Contact Surfaces. J Food Saf 37: e12287.

38. Keeratipibul S, Laovittayanurak T, Pornruangsarp O, Chaturongkasumrit $Y$, Takahashi $\mathrm{H}$, et al. (2017) Effect of swabbing techniques on the efficiency of bacterial recovery from food contact surfaces. Food Control 77: 139-144.

39. Locascio LE, Harper B, Robinson M, Badar T (2007) Standard practice for bulk sample collection and swab sample collection of visible powders suspected of being biological agents from nonporous surfaces: collaborative study. J Assoc Off Anal Chem 90: 299.

40. Pazienza M, Britti M, Carestia M, Cenciarelli O, D'Amico F, Malizia A, et al. (2013) Application of real-time PCR to identify residual bio-decontamination of confined environments after hydrogen peroxide vapor treatment: preliminary results. J Microb Biochem Technol 6: 24-8.

41. Hassan M, Gonzalez E, Hitchins V, llev I (2016) Detecting bacteria contamination on medical device surfaces using an integrated fiber-optic midinfrared spectroscopy sensing method. Sens Actuators B Chem 231: 646-654.

42. Everard CD, Kim MS, Lee H (2016) Assessment of a handheld fluorescence imaging device as an aid for detection of food residues on processing surfaces. Food Control 59: 243-249.

43. Vejarano R, Siche R, Tesfaye W (2017) Evaluation of biological contaminants in foods by hyperspectral imaging: A review. Int J Food Prop 20: 1264-1297.

44. Luger HM, Barbiro ME, Sonn J, Mayevsky A (2009) Renal viability evaluated by the multiprobe assembly: A unique tool for the assessment of renal ischemic injury. Nephron Clin Pract 111: 29-38.

45. Buschke DG, Squirrell JM, Fong JJ, Eliceiri KW, Ogle BM (2012) Cell death, non-invasively assessed by intrinsic fluorescence intensity of $N A D H$, is a predictive indicator of functional differentiation of embryonic stem cells. Biol Cell 104: 352-364.

46. Wang HW, Wei YH, Guo HW (2009) Reduced nicotinamide adenine dinucleotide (NADH) fluorescence for the detection of cell death. Anti-Cancer Agents Med Chem 9: 1012-1017.

47. Pan YL (2015) Detection and characterization of biological and other organiccarbon aerosol particles in atmosphere using fluorescence. J Quant Spectrosc Radiat Transf 150: 12-35.

48. 48. Fraser D, Jerrel EA (1953) The amino acid composition of T3 bacteriophage. J Biol Chem 205: 291-295.

49. Hooker JM, Kovacs EW, Francis MB (2004) Interior surface modification of bacteriophage MS2. J Am Chem Soc 126: 3718-3719.

50. Ledford H (2008) How does bleach bleach? Nature. 